\title{
Impact of Asymptomatic Malaria on Some Hematological Parameters in the Iwo Community in Southwestern Nigeria
}

\author{
Christopher Igbeneghu ${ }^{a} \quad$ Alex B. Odaibo $^{b}$ David O. Olaleye ${ }^{c}$ \\ a Department of Biomedical Sciences, Faculty of Basic Medical Sciences, Ladoke Akintola University of \\ Technology, Ogbomoso; ${ }^{b}$ Department of Zoology, Parasitology Unit, and ' Department of Virology, \\ College of Medicine, University of Ibadan, Ibadan, Nigeria
}

\section{Key Words}

Blood donors $\cdot$ Asymptomatic malaria $\cdot$ Hematological parameters

\begin{abstract}
Objective: To determine the prevalence of asymptomatic malaria among prospective blood donors and its effect on some hematological parameters. Subjects and Methods: Six hundred sixty-eight seemingly healthy individuals (501 men and 167 women) $\geq 16$ years of age and without clinical symptoms in Iwo, Southwestern Nigeria, were screened for this study. A sample of $5 \mathrm{ml}$ of blood was drawn from each participant for examination of malaria parasites and a full blood count. Thick and thin Giemsa-stained blood smears were prepared for malaria parasite identification and quantification. Estimations of hematocrit, hemoglobin concentration, and platelet and leukocyte counts were made using an automated Coulter counter (STKS model). Results: Out of the 668 participants examined, 141 (21.1\%) were positive for malarial parasitemia. The parasite rate was significantly higher in men $(25.5 \%)$ than in women $(7.8 \%)\left(\chi^{2}=23.29, p<0.001\right)$ and it was significantly associated with age $\left(\chi^{2}=33.69, \mathrm{p}<\right.$ 0.001 ). Parasitemic participants had significantly lower mean values of hematocrit, hemoglobin concentration, and total leukocyte and platelet counts compared to aparasitemic individuals $(\mathrm{t}=3.5, \mathrm{p}<0.001 ; \mathrm{t}=2.0, \mathrm{p}=0.04 ; \mathrm{t}=4.4, \mathrm{p}<0.001$,
\end{abstract}

and $t=5.3, p<0.001$, respectively). A low platelet count $\left(<150 \times 10^{9} /\right.$ l) $)$ was significantly associated with malarial infection (OR 4.0; 95\% Cl 2.6-6.1). A person with a platelet count $<150 \times 10^{9} / \mathrm{I}$ was 4 times more likely to have asymptomatic malarial infection than one with a count $\geq 150 \times$ $10^{9} /$. Conclusion: Asymptomatic malaria is prevalent among blood donors in the study area and is associated with thrombocytopenia.

Copyright $\odot 2011$ S. Karger AG, Basel

\section{Introduction}

Asymptomatic malaria is prevalent in highly endemic areas of Africa, with only a small percentage of individuals exhibiting clinical symptoms [1]. The clinical consequence of asymptomatic malaria is not fully understood. Some researchers are of the view that asymptomatic parasitemia is involved in the development of partial immunity [2] and may protect against clinical disease from new infections [3]. Also, there are reports that asymptomatic parasitemia provides a reservoir for transmission and may be a precursor in the progression to symptomatic disease [1]. Findings on presumptive therapy for asymptomatic parasitemia have shown that it can significantly reduce malaria-associated morbidity [4]. Alves et al. [5] showed that active case finding and treatment of patients 
Table 1. Prevalence of asymptomatic malaria by sex and age among the study population

\begin{tabular}{lll}
\hline Sex $^{\mathrm{a}}$ & Examined, $\mathrm{n}(\%)$ & Infected, $\mathrm{n}(\%)$ \\
\hline Female & $167(25.0)$ & $13(7.8)$ \\
Male & $501(75.0)$ & $128(25.5)$ \\
\cline { 2 - 3 } Total & $668(100.0)$ & $141(21.1)$ \\
\hline Age ${ }^{\mathrm{b}}$, years & & \\
$16-19$ & $65(9.7)$ & $17(26.2)$ \\
$20-29$ & $263(39.4)$ & $76(28.9)$ \\
$30-39$ & $172(25.7)$ & $30(17.4)$ \\
$40-49$ & $99(14.8)$ & $12(12.1)$ \\
$50-59$ & $5(6.7)$ & $1(4.2)$ \\
$\geq 60$ & $24(3.6)$ & $141(21.1)$ \\
Total & $668(100.0)$ & \\
\hline \multicolumn{2}{c}{$\chi^{2}=23.29$, d.f. $=1 ; \mathrm{p}<0.001 .{ }^{\mathrm{b}} \chi^{2}=33.69$, d.f. $=5 ; \mathrm{p}<0.001}$. \\
\hline
\end{tabular}

with subpatent, asymptomatic parasitemia would be critical for the control of malaria in an endemic area.

Although there are many reports on asymptomatic malaria in endemic areas, its effect on hematological parameters has not been well documented. This study was aimed at determining the effect of asymptomatic malaria on some hematological parameters among seemingly healthy prospective blood donors in the Iwo community in Southwestern Nigeria.

\section{Subjects and Methods}

Study Area and Population

The study was carried out in Iwo, a semiurban community about $45 \mathrm{~km}$ from Ibadan in Southwestern Nigeria. A total of 668 prospective blood donors ( 167 women and 501 men) with no clinical signs or symptoms of ill health as of the time of the investigation were screened for this study after clinical examination, and informed consent was obtained. Ethical approval for this study was obtained from the Joint Ethical Committee of Ladoke Akintola University Teaching Hospital, Osogbo, and Ladoke Akintola University of Technology, Ogbomoso, Nigeria.

A sample of $5 \mathrm{ml}$ of venous blood was collected from each participant into ethylenediaminetetraacetic acid (EDTA) bottles for laboratory investigations. Thick and thin blood films stained with $3 \%$ Giemsa were examined for estimation and identification of malaria parasites. At least 200 microscopic fields were examined before declaring a smear as negative. The number of parasites present in each thick film in 200-leukocyte counts was determined (if less than 10 parasites were counted, counting was continued to 500 leukocytes). For the positive slides, the number of parasites counted per 200 or 500 leukocytes was used to calculate parasite density on the basis of the individual's true leukocyte
Table 2. Levels of parasitemia by sex and age among the parasitemic subjects

\begin{tabular}{|c|c|c|c|c|}
\hline \multirow[t]{2}{*}{ Parameter } & \multicolumn{4}{|c|}{ Parasite density distribution, parasites/ $\mu \mathrm{l}$} \\
\hline & $<500$ & $500-999$ & $\geq 1,000$ & total \\
\hline \multicolumn{5}{|l|}{$\operatorname{Sex}^{\mathrm{a}}$} \\
\hline Female & $7(5.0)$ & $4(2.8)$ & $2(1.8)$ & $13(9.2)$ \\
\hline Male & $90(63.8)$ & $22(15.6)$ & $16(11.3)$ & $128(90.8)$ \\
\hline Total & $97(68.8)$ & $26(18.4)$ & $18(12.8)$ & $141(100.0)$ \\
\hline \multicolumn{5}{|l|}{ Age $^{\mathrm{b}}$, years } \\
\hline $16-19$ & $11(5.7)$ & $3(1.4)$ & $3(1.4)$ & $17(8.5)$ \\
\hline $20-29$ & $56(30.5)$ & $11(5.0)$ & $9(5.7)$ & $76(41.1)$ \\
\hline $30-39$ & $21(21.3)$ & $5(2.1)$ & $4(2.8)$ & $30(26.2)$ \\
\hline $40-49$ & $6(8.5)$ & $4(4.3)$ & $2(2.1)$ & $12(14.9)$ \\
\hline $50-59$ & $3(2.1)$ & $2(2.8)$ & $0(0.7)$ & $5(5.7)$ \\
\hline$\geq 60$ & $0(0.7)$ & $1(2.8)$ & $0(0.0)$ & $1(3.5)$ \\
\hline Total & $97(68.8)$ & $26(18.4)$ & $18(12.8)$ & $141(100.0)$ \\
\hline
\end{tabular}

count per microliter of blood. Full blood counts were done using an automated Coulter counter (STKS model).

Statistical Analysis

Differences between percentages and proportions were examined using a $\chi^{2}$ test. Sample means were compared by Student's $t$ test. Linear relationships between 2 variables were determined by Pearson's correlation coefficient. $p<0.05$ was considered statistically significant.

\section{Results}

The mean age of the 668 participants was $33 \pm 12$ years (range 16-67). The prevalence of asymptomatic malarial infection among the study population in relation to sex and age is given in table 1 . Of the 668 participants, 141 (21.1\%) comprising 128 (25.5\%) of the 501 men and 13 (7.8\%) of the 167 women had asymptomatic malaria. Men were significantly more infected than women $\left(\chi^{2}=23.29\right.$, $\mathrm{p}<0.001)$. Malarial infection varied significantly with age $\left(\chi^{2}=33.69, \mathrm{p}<0.001\right)$. Two Plasmodium spp.: Plasmodium falciparum and Plasmodium malariae were identified among the subjects. Of the 141 subjects infected, 136 (96.5\%) had P. falciparum, 2 (1.4\%) had P. malariae, and 3 (2.1\%) had mixed $P$. falciparum and $P$. malariae.

The frequency of distribution of parasite densities among the asymptomatic malarial participants with re- 
Table 3. Comparison of age and mean hematological values of apparently healthy aparasitemic and parasitemic subjects

\begin{tabular}{lcccc}
\hline Parameter & $\begin{array}{l}\text { Aparasitemic } \\
\text { subjects }(\mathrm{n}=527)\end{array}$ & $\begin{array}{l}\text { Parasitemic } \\
\text { subjects }(\mathrm{n}=141)\end{array}$ & t value & p value \\
\hline Age, years & $34.0 \pm 12.1$ & $31.9 \pm 11.1$ & 2.0 & 0.04 \\
Hematocrit, \% & $39.5 \pm 4.0$ & $38.1 \pm 4.3$ & 3.5 & $<0.001$ \\
Hemoglobin concentration, g/l & $136.9 \pm 13.4$ & $134.2 \pm 14.2$ & 2.0 & 0.04 \\
Leukocyte count, $10^{9} / 1$ & $5.3 \pm 2.1$ & $4.6 \pm 1.4$ & 4.4 & $<0.001$ \\
Platelet count, $10^{9} / 1$ & $163.2 \pm 29.5$ & $150.1 \pm 29.2$ & 5.3 & $<0.001$ \\
\hline
\end{tabular}

Values are presented as means $\pm \mathrm{SD}$.

spect to age and sex is shown in table 2. Ninety-seven $(68.8 \%)$ of the asymptomatic malarial participants had parasite densities $<500 / \mu l$. The mean parasite density was $5.37 \pm 8.52 \times 10^{2} / \mu l$ (range $0.32 \times 10^{2} / \mu l-7.84 \times$ $\left.10^{3} / \mu \mathrm{l}\right)$. There was no significant difference in the levels of parasitemia between the sexes $\left(\chi^{2}=1.66, p=0.2\right)$, but there was a significant difference in the levels parasitemia among the age groups $\left(\chi^{2}=16.44, \mathrm{p}=0.02\right)$.

The hematological values of the aparasitemic and parasitemic subjects in the study population are given in table 3. Parasitemic subjects were significantly younger than aparasitemic individuals. The hematocrit, hemoglobin concentration, and leukocyte and platelet counts were significantly lower in parasitemic subjects compared to nonparasitemic individuals. There was a significant inverse correlation between parasite density and hemoglobin concentration $(\mathrm{r}=-0.20, \mathrm{p}=0.02)$. However, there was no significant correlation between parasite density and: (i) leukocyte count $(\mathrm{r}=-0.12, \mathrm{p}=0.15)$, (ii) platelet count $(\mathrm{r}=0.05, \mathrm{p}=0.55)$, and (iii) age $(\mathrm{r}=-0.03$, $\mathrm{p}=0.73)$.

Categorical variables were created from 3 of the hematological parameters, i.e. hemoglobin concentration and leukocyte and platelet counts. The result of the odd ratio showed that there was no significant association between anemia (women $<120 \mathrm{~g} / 1$; men $<130 \mathrm{~g} / \mathrm{l}$ ) and asymptomatic malaria (OR 1.2, 95\% CI 0.9-1.5) or between a low leukocyte count $\left(<2.6 \times 10^{9}\right)$ and asymptomatic malaria (OR 1.4, 95\% CI 0.6-3.4), but there was a significant association between a low platelet count $\left(<150 \times 10^{9} / \mathrm{l}\right)$ and asymptomatic malaria (OR 4, 95\% CI 2.6-6.1). A platelet count $<150 \times 10^{9} / 1$ was 4 times more likely to occur in persons with malarial parasitemia than in those without it.

\section{Discussion}

The prevalence rate of asymptomatic malaria of $21.1 \%$ reported in this study was similar to the rates reported in previous studies from the same region $[6,7]$. Malaria in this region is holoendemic; transmission is high and occurs year-round without any marked fluctuations over the years, though seasonal variations may exist [8].

In this study, parasite rates decreased significantly with age and the majority of the parasitemic participants had low parasite densities, though a few had fairly high parasite densities. The age-dependent decrease in parasite rates has also been observed in previous studies [7, 9] and is explained by a continued increase in immunity well into adult age [10]. The prevalence and age distribution of asymptomatic parasitemia vary widely and have been associated with transmission intensity and the development of partial immunity [2]. An appreciable number of adults in a holoendemic area like the one in this study are expected to be positive for malaria parasites without exhibiting the signs and symptoms. While the risk of infection increases with transmission intensity, the risk of symptomatic disease per infection is inversely related to the intensity of transmission and age-dependent acquisition of partial immunity [10].

Two Plasmodium spp., i.e. P. falciparum and P. malariae, were detected among the parasitemic individuals in this study unlike in other studies where the presence of all 4 human Plasmodium spp. in Nigeria were reported [11-13]. However, the distributions of the species are not even across the country [8]. While P. falciparum is the most common of these parasites, Plasmodium vivax is rare because this population lacks the Duffy blood group antigens on their red blood cells. 
Although the results of this study show a significant decrease in the mean values of hemoglobin concentration and platelet and leukocyte counts of asymptomatic malarial subjects compared to nonmalarial subjects, only a low platelet count $\left(<150 \times 10^{9} / 1\right)$ showed a significant association with asymptomatic malaria.

Anemia has been associated with chronic malaria resulting from dyserythropoiesis and ineffective erythropoiesis [14]. These mechanisms could be responsible for the decrease in the hemoglobin level observed among the seemingly healthy parasitemic subjects. A report suggested that persistent asymptomatic malarial infections significantly increase the risk of becoming anemic [15].

The mechanism of a low platelet count associated with asymptomatic malaria in this study could be similar to that observed with acute malarial infection, which is not fully understood. It is thought to be due to peripheral destruction and consumption [16]. Immune complexes generated by malarial antigens lead to sequestration of the injured platelets by macrophages in the spleen. Also, platelet consumption in disseminated intravascular coagulation is thought to contribute to thrombocytopenia in malaria [16]. Platelet dysfunction resulting in hyperaggregation is another alteration occurring in association with malaria $[16,17]$. Platelets activated by such factors as formation of immune complexes, damage of endothelial cells, and surface contact of platelets with parasitized red blood cells could easily undergo intravascular lysis [18].

The lower leukocyte count observed among the parasitemic subjects compared to aparasitemic subjects in this study could be due to a reduced lymphocyte count which has been associated with acute malaria where depletion in the lymphocyte subsets through apoptosis [19] or se- questration of the cells in the lymph nodes or other body tissues is said to be responsible for the occurrence of leukopenia [20].

Transfusion of Plasmodium-infected blood to immune adults may not result in clinical malaria but may be hazardous to nonimmune patients such as pregnant women whose immunity is lost and children whose immunity is yet to fully develop. In Sub-Saharan Africa, where blood donors are usually not screened for malarial parasites, this study shows that the platelet count can play a useful role in screening out blood donors with asymptomatic malaria as a blood donor with a platelet count $<150,000 / \mu l$ is more likely to have malarial infection compared to one with a count $\geq 150,000 / \mu l$. Although the current standard practice is to administer curative regimens of antimalarial drugs to all recipients of blood transfusions, the use of platelet counts can increase the chances of administering Plasmodium-free blood particularly to nonimmune patients among whom cases of transfusion malaria have been reported [21].

\section{Conclusion}

Although subjects with asymptomatic malaria had lower mean hematological values compared to noninfected subjects, severe cases were not observed and only a low platelet count showed a significant association with asymptomatic malaria.

\section{Acknowledgements}

We are grateful to the Managements and Staff of Bowen Baptist and Victory Hospitals, both in Iwo, Nigeria, for their invaluable cooperation and support during the course of this study.

\section{References}

1 Dal-Bianio MP, Koster KB, Kombila UD, Kun JF, Grobusch MP, Ngoma GM, Matsiequi PB, Supan C, Salazar CL, Missinou MA, Issifou S, Lell B, Kremsner P: High prevalence of asymptomatic Plasmodium falciparum infection in Gabonese adults. Am J Trop Med Hyg 2007;77:939-942.

$\checkmark 2$ Staalsoe T, Hviid L: The role of variant-specific immunity in asymptomatic malaria infections: maintaining a fine balance. Parasitol Today $1998 ; 14: 177-178$.

\footnotetext{
3 Farnert A, Arez AP, Correia AT, Bjorkman A, Snounou G, do Rosario V: Sampling and storage of blood and the detection of malaria parasites by polymerase chain reaction. Trans R Soc Trop Med Hyg 1999;93: 50-53.

4 Desai MR, Mei JV, Kariuki SK: Randomized, controlled trial of daily iron supplementation and intermittent sulfadoxine-pyrimethamine for the treatment of mild childhood anaemia in western Kenya. J Infect Dis 2003;187:658-666.
}

\footnotetext{
5 Alves FP, Durlacher RR, Menezes MJ, Krieger H, Silva LH, Camargo EP: High prevalence of asymptomatic Plasmodium vivax and Plasmodium falciparum infections in native Amazonian populations. Am J Trop Med Hyg 2002;66:641-648.

6 Ademowo OG, Falusi AG, Mewoyeka OO: Prevalence of asymptomatic parasitaemia in an urban and rural community in Southwestern Nigeria. Cent Afr J Med 1995;41:1821.
} 
7 Achidi EA, Perlmann H, Berzins K: Asymptomatic malaria parasitaemia and seroreactivities to Plasmodium falciparum antigens in blood donors from Ibadan, Southwestern Nigeria. Ann Trop Med Parasitol 1995;89. 601-610.

8 Federal Ministry of Health of Nigeria. National malaria and vector control. Abuja, FMOH, 2005.

$\checkmark 9$ Baliraine FN, Afrane YA, Amenya DA, Bonizzoni M, Menge DM, Zhou G, Zhong D, Vardo-Zalik AM, Githeko AK, Yan G: High prevalence of asymptomatic Plasmodium falciparum infections in a highland area of western Kenya: a cohort study. J Infect Dis 2009;200:66-74

10 Rogier C, Commenges D, Trape JF: Evidence for an age-dependent pyrogenic threshold of Plasmodium falciparum parasitemia in highly endemic populations. Am J Trop Med Hyg 1996;54:613-619.

11 May J, Mockenhaupt FP, Ademowo OG, Falusi AG, Olumese PE, Bienzle U, Meyer CG: High rate of mixed and subpatent malarial infections in Southwest Nigeria. Am J Trop Med Hyg 1999;61:339-343.
Erhabor O, Babatunde S, Uko KE: Some haematological parameters in plasmodial parasitized HIV-infected Nigerians. Niger J Med 2006;15:52-55.

13 Molineaux L, Storey J, Cohen JE, Thomas A: A longitudinal study of human malaria in the West African Savanna in the absence of control measures: relationships between different Plasmodium species, in particular $P$. falciparum and P. malariae. Am J Trop Med Hyg 1980;29:725-737.

14 Abdalla S, Weatherall DJ, Wickramasingle SH, Hughes M: The anaemia of Plasmodium falciparum malaria. Br J Haematol 1980;46: 171-183.

15 Mayor A, Aponte JJ, Fogg C, Saute F, Greenwood B, Dgedge M, Menendez C, Alonso PL: The epidemiology of malaria in adults in a rural area of Southern Mozambique. Malar J 2007;6:3.

16 Erhart LM, Yingyuen K, Chuanak N, Buathong N, Laoboonchai A, Miller RS, Meshnick SR, Gasser RA, Wongsrichanalai C: Haematologic and clinical indices of malaria in a semi-immune population of western Thailand. Am J Trop Med Hyg 2004;70: $8-14$
17 Mohanty D, Marwaha N, Ghosh K, Sharma S, Garewal G, Shah S, Devi S, Das KC: Functional and ultrastructural changes of platelets in malaria infection. Trans $\mathrm{R}$ Soc Trop Med Hyg 1988;82:369-375.

18 Essien EM: The circulating platelet in acute malaria infection. Br J Haematol 1989;72: 589-590.

19 Dodoo D, Omer FM, Todd J: Absolute levels and ratios of pro-inflammatory and anti-inflammatory cytokine production in vitro predict clinical immunity to Plasmodium falciparum malaria. J Infect Dis 2002;185: 971-979.

20 Oh MD, Shin H, Shin D, Kim U, Kin N, Chol $\mathrm{MH}$, Chai JY, Choe K: Clinical features of vivax malaria. Am J Trop Med Hyg 2001;65: 143-146.

21 Ibhanesebhor SE, Otobo ES, Ladipo OA prevalence of malaria parasitaemia in transfused donor blood in Benin City, Nigeria. Ann Trop Paediatr 1996;16:93-95. 